\title{
Enhancement on the Performance of Refrigeration System Using the Nano-Refrigerant
}

\author{
Qasim S. Mahdi, Maathe A. Theeb and Hisham Saed \\ Mechanical Engineering Department, Faculty of Engineering, Al-Mustansiriyah University, Baghdad 10001, Iraq
}

Received: February 07, 2017 / Accepted: February 13, 2017 / Published: April 30, 2017.

\begin{abstract}
The purpose of the present experimental work is to investigate the performance (1 ton) refrigeration system using nano-refrigerant. Nano-refrigerant is alumina $\left(\mathrm{r}-\mathrm{Al}_{2} \mathrm{O}_{3}\right)$ nanopartcal with size $(20-30) \mathrm{nm}$ is dispersed into $\mathrm{R}-134 \mathrm{a}$ with volume fraction $0.01 \%$ and $0.02 \%$. The experimental test rig consists of horizontal double tube counter flow heat exchanger fabricated of copper. The nano-refrigerant is evaporated inside the inner tube because of the heat gain from hot water passing in the annulus surrounding the inner tube. The experimental results indicate, when increasing the volume concentration of $\mathrm{Al}_{2} \mathrm{O}_{3}$ refrigerant by $0.01 \%$ and $0.02 \%$, the heat transfer coefficient increases by $0.54 \%$ to $1.1 \%$. The thermal conductivity increases by $11.5 \%$ and $14.2 \%$, respectively, while the coefficient of performance increases by $3.33 \%$ to $12 \%$, respectively. The heat transfer rate in the refrigeration side is enhancement about $6.7 \%$ to $21.4 \%$ compared with conventional refrigerant, and the power consumption by compressor is decreased by nearly $1.6 \%$ and $3.3 \%$, respectively.
\end{abstract}

Key words: Nano-refrigerant, $\mathrm{R} 134 \mathrm{a}$, alumina $\left(\mathrm{Al}_{2} \mathrm{O}_{3}\right)$, tube in tube heat exchanger, heat transfer enhancement.

\section{Nomenclature}

$\begin{array}{ll}C p & \text { Specific heat }\left(\mathrm{J} / \mathrm{kg} \cdot{ }^{\circ} \mathrm{C}\right) \\ k & \text { Thermal conductivity }\left(\mathrm{W} / \mathrm{m} \cdot{ }^{\circ} \mathrm{C}\right) \\ h & \text { Heat transfer coefficient }\left(\mathrm{W} / \mathrm{m}^{2} \cdot \mathrm{k}\right) \\ Q & \text { Heat transfer rate }(\mathrm{W}) \\ \dot{m} & \text { Mass flow rate }(\mathrm{kg} / \mathrm{s}) \\ m & \text { Mass of the nanoparticle }(\mathrm{g})\end{array}$

\section{Greek Letter}

$\begin{array}{ll}\rho & \text { Density } 1\left(\mathrm{~kg} / \mathrm{m}^{3}\right) \\ \mu & \text { Dynamic viscosity }(\mathrm{kg} / \mathrm{m} \cdot \mathrm{s}) \\ \varnothing & \text { Naonparticle volume fraction }\end{array}$

\section{Introduction}

Most of the refrigeration systems use Vapour Compression Refrigeration with used double tube heat exchanger and suspended $\mathrm{Al}_{2} \mathrm{O}_{3}$ nanoparticle in the R134a with many concentration to enhance the thermal performance of nano-refrigerant because better thermal conductivity on nanoparticle and more

Corresponding author: Hisham Saed, mechanical engineer, research field: thermodynamic heat transfer. heat transfer reduced the power consumption.

Senthilkumar and Praveen [1] studied experimentally the performance of a domestic refrigeration by using $\mathrm{CuO}-\mathrm{R} 600 \mathrm{a}$ nano-refrigerant. In this investigated refrigeration a method used the natural gas to improve the energy efficiency of refrigeration. The average particle diameter is $50 \mathrm{~nm}$ and the purity is $99.5 \%$, the concentration of the nano in the refrigeration is 0.1 and $0.5 \mathrm{~g} / \mathrm{L}$. The result indicated that the freezing velocity is quick than the pure R600a, and the saving energy consumption is about $11.83 \%$ and $17.88 \%$.

Bi et al. [2] studied experimentally the performance of a domestic refrigerator using $\mathrm{TiO}_{2}-\mathrm{R} 600 \mathrm{a}$ nano-refrigerant as working fluid. Thermal conductivity and heat transfer characteristics were increasing when using the nanoparticle, the concentration when suspended in the R600a is 0.1 and $0.5 \mathrm{~g} / \mathrm{L}$ and the average diameter is $50 \mathrm{~nm}$. The test results indicated that $\mathrm{TiO}_{2}-\mathrm{R} 600 \mathrm{a}$ can work normally and efficiently in refrigerator. Compared with 
refrigerator using pure R600a as working fluids, it can save $5.94 \%$ and $9.60 \%$ energy consumption respectively and the freezing velocity of nano-refrigerant system was more quickly than the pure R600a system. Kuljeet and Kundan [3] studied the performance of a refrigeration system when using nano-refrigerant $\left(\mathrm{R} 134 \mathrm{a}+\mathrm{Al}_{2} \mathrm{O}_{3}\right)$. The purpose in this study is to improve thermal physical properties over the conventional refrigerants, using domestic refrigerator. The results presented that coefficient of performance of domestic refrigerator can be improved by mixing $\mathrm{Al}_{2} \mathrm{O}_{3}$ nanoparticles in base refrigerant R134. Mahbubul et al. [4] studied about thermophysical properties and heat transfer performance of $\mathrm{Al}_{2} \mathrm{O}_{3} / \mathrm{R}-134 \mathrm{a}$ nano-refrigerant, to determine the thermal conductivity and viscosity of the nano-refrigerant. It used a horizontal smooth tube. The results revealed that thermal conductivity of the nano-refrigerant increases when increasing nanoparticle volume fraction and temperature, but decreases if increasing the particle size. And the viscosity of nano-refrigerant also increases with the augmentation of nanoparticles concentrations. Fadhilah et al. [5] used copper oxide nanoparticles for studied refrigerant thermophysical properties. The design double tube heat exchanger is made of copper. A study proved that the nanoparticles suspension in domestic refrigerators R134a could reduce the energy consumption and improve coefficient of performance of the refrigeration system. The investigation includes enhancing the thermophysical properties.

Tarun and Kundan [6] investigated the performance of refrigeration system with nano-refrigerant to reduce the power consumption and enhance the heat transfer capacity of refrigerant. It used in this study $\mathrm{Al}_{2} \mathrm{O}_{3}$ with 20-30 nm mixed with R134a. The test rig evaporator section coil type is load with water. The experimental results are enhancement in the thermo physical properties, and heat transfer characteristics of the refrigeration system, enhancement in COP, a reduction in the power consumption $(10.87 \%$ \&
$13.04 \%)$, faster cooling from (41c-25c), and more temperature drop in the condenser.

The aim of the present paper is to investigate the performance of (1 ton) refrigerant system when using $\mathrm{Al}_{2} \mathrm{O}_{3}$ with $\mathrm{R}-134 \mathrm{a}$ as a refrigerant, and to study enhancing the thermophysical properties of nano-refrigerant, power consumption, and the heat transfer rate.

\section{Experimental Test Rig}

The experimental test rig consists of reciprocating hermetic compressor condenser, expansion valve and the evaporating is counter flow double tube heat exchanger as shown in Fig. 1. The refrigerant used in the system is R-134a. The experimental test section is a straight double tube counter flow heat exchanger which is made of copper. The length of test section is $1,100 \mathrm{~mm}$, the inner diameter and the thickness are 21 $\mathrm{mm}$ and $1 \mathrm{~mm}$, respectively. The outer tube diameter and the thickness are $44 \mathrm{~mm}$ and $1 \mathrm{~mm}$ respectively as shown in Fig. 2. The refrigerant is flow in the inner tube and the hot water passes through annulus. The hot water circuit consists of water tank with electrical heater (2,000 Watt), water pump pipes insulated and fitting, and rotameter to measure the flow rate.

\section{Preparation of the $\left(\mathrm{Al}_{2} \mathrm{O}_{3}-\mathrm{R} 134 \mathrm{a}\right)$ Nano-Refrigerant}

Nano-refrigerant was prepared in a recommended method for nanofluid. The nanoparticle $\mathrm{Al}_{2} \mathrm{O}_{3}$ was mixed with refrigerant R-134a by using vibrated ultrasonic oscillator. The average particle of $\mathrm{Al}_{2} \mathrm{O}_{3}$ diameter is about $20-30 \mathrm{~nm}$ and the mass purity is 99.5\% in this investigation using some correlation of thermo physical properties of $\mathrm{Al}_{2} \mathrm{O}_{3} / \mathrm{R}-134 \mathrm{a}$. Some constant properties of $\mathrm{Al}_{2} \mathrm{O}_{3}$ are shown in Table 1 [8]

Table 1 The properties of $\mathrm{Al}_{2} \mathrm{O}_{3}$.

\begin{tabular}{ll}
\hline Density $\left(\mathrm{kg} / \mathrm{m}^{3}\right)$ & 3,970 \\
Thermal conductivity $(\mathrm{W} / \mathrm{m} \cdot \mathrm{K})$ & 40 \\
Specific heat $(\mathrm{J} / \mathrm{kg} \cdot \mathrm{K})$ & 765 \\
\hline
\end{tabular}



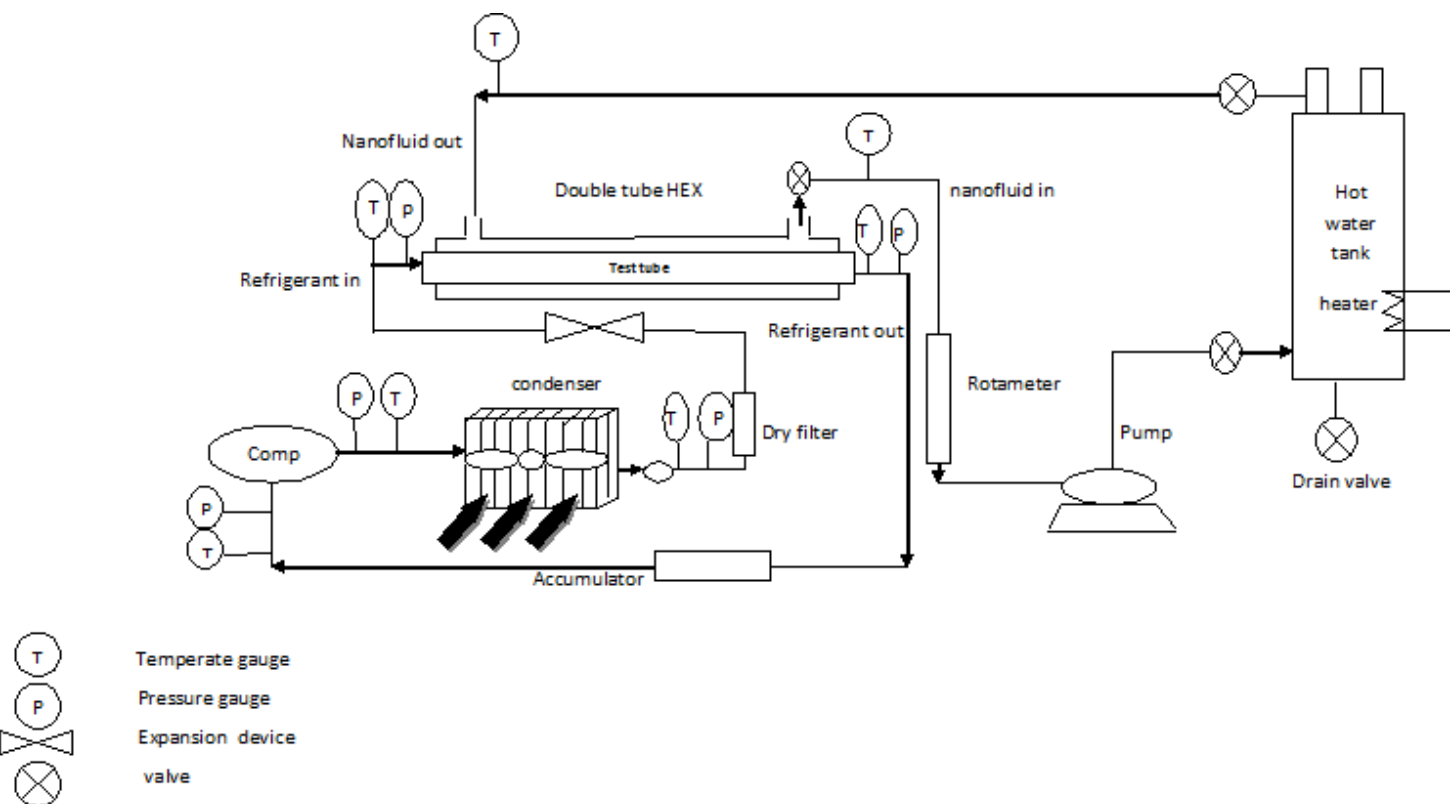

Fig. 1 Schematic diagram for the experimental test rig.

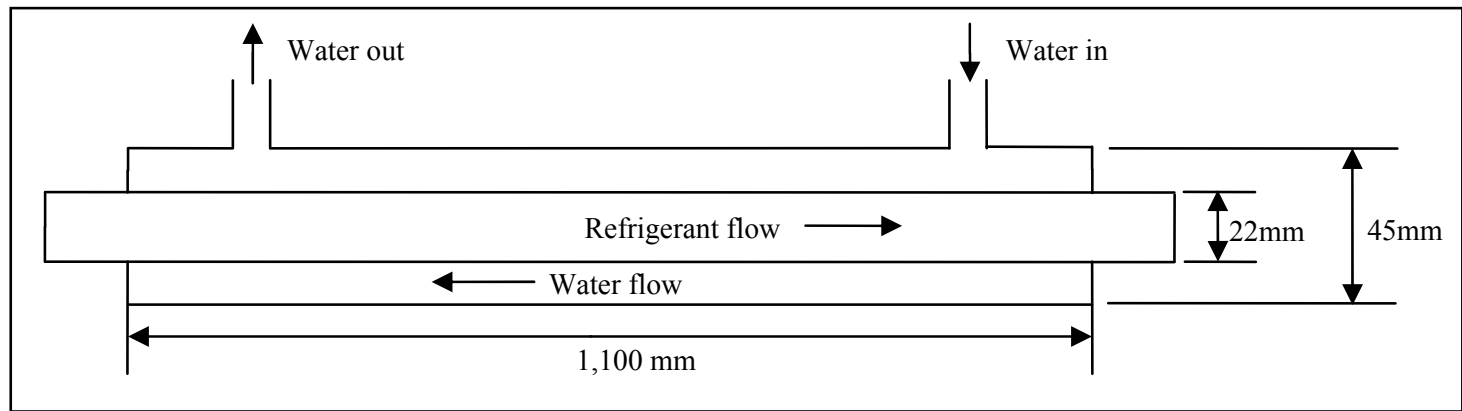

Fig. 2 The test section.

that the concentration is $0.01 \%-0.02 \%$ and the average diameter is $20-30 \mathrm{~nm}$ [7].

The thermo-physical properties of nano-refrigerant are the following.

The volume fraction $(\varnothing)$ of nano-refrigeration can be estimated by the following Eq. (1) [9].

$$
\emptyset=\frac{m_{n} / \rho_{n}}{m_{n} / \rho_{n}+m_{r} / \rho_{r}}
$$

where, $n$ and $r$ refer to nanoparticle, pure refrigerant liquid phase.

The viscosity of nano-refrigerant has been influenced by the particle size of nanoparticle and the concentration and conventional refrigeration. It can be calculated by using the following Eq. (2) [10].

$$
\mu_{r-n, L}=\mu_{r, L} \frac{1}{(1-\emptyset)^{2.5}}
$$

where, $\mu_{r-n, L}$ is the viscosity of liquid nano-refrigerant, $\mu_{r, L}$ is viscosity of liquid pure refrigerant.

The thermal conductivity of nano-refrigerant is calculated by mathematical model as follows [11].

$$
\frac{K_{n f}}{K_{r}}=\mathrm{C} \mathrm{Re}_{m}^{0.175} \emptyset_{P}^{0.05}\left(\frac{K_{p}}{K_{m}}\right)^{0.2324}
$$

where, $n f$ refers to nanofluid, $r$ is pure of refrigerant, $\mathrm{C}$ is constant in this equation (1.298).

The Reynolds number of nano-refrigerant is calculated by using

$$
\operatorname{Re}_{\mathrm{m}}=\left(\frac{1}{v_{m}}\right)\left(\frac{18 K_{P} T_{i n}}{\pi \rho_{P} d_{p}}\right)^{1 / 2}
$$

where, $v_{m}$ is the velocity of refrigerant, $\rho_{\mathrm{p}}$ is the density of nanoparticle. 
The coefficient of performance of refrigerant system is shown by the following Eq. (5).

$$
\operatorname{COP}_{n-r}=\frac{h_{1}-h_{4}}{h_{2}-h_{1}}
$$

The heat transfer rate of nano-refrigerant can be obtain by the following Eq. (6) [12].

$$
Q_{r-n}=\dot{m}_{r-n} \mathrm{Cp}_{r-n} \Delta T
$$

where, $\Delta T$ is different temperature of nano-refrigerant in double tube heat exchanger.

To obtain the power consumption of the test rig it is calculated by using the following Eq. (7) [13].

$$
\text { Power consumption }=V \times I
$$

\section{Result and Discussion}

Fig. 3 shows that the viscosity increases $1.4 \%$ and $5.2 \%$ respectively with the increase of volume fraction, compared with conventional refrigerant. The suspended $\mathrm{Al}_{2} \mathrm{O}_{3}$ nanoparticles have increased the surface area that offers more contact between $\mathrm{R}-134 \mathrm{a} / \mathrm{Al}_{2} \mathrm{O}_{3}$.

Fig. 4 shows the relationship between the thermal conductivity and volume fraction. Thermal conductivity $K_{n f}$ is influenced by the particle volume fraction. The enhancement of thermal conductivity of two volume concentration 0.01 and $0.02 \%$ increases about $11.5 \%$ and $14.2 \%$.

Fig. 5 observes that $\mathrm{Al}_{2} \mathrm{O}_{3} / \mathrm{R}-134 \mathrm{a}$ mixture is highest COP when compared with pure refrigerant.
COP is related to power consumption, the higher COP is, the less power consumption of the system. The COP increment is about $3.33 \%$ to $12 \%$ compared without nano-refrigerant, when the volume concentrations are $0.01 \%$ and $0.02 \%$ respectively.

Fig. 6 indicates the influence of the $\mathrm{Al}_{2} \mathrm{O}_{3}$ nanoparticle volume fraction on the heat rate of nano-refrigerant which is transferred from center tube of refrigerant to the wall. It can be demonstrated that the heat rate is proportional to the particle volume fraction. It is indicated that the increase of the heat rate is from $6.7 \%$ to $21.4 \%$ compared without nanoparticle.

Fig. 7 demonstrates the influence of the $\mathrm{Al}_{2} \mathrm{O}_{3}$ nanoparticle concentration on the convective heat transfer coefficient. It can be showed that the heat transfer coefficient is proportional to the particle volume fraction. When increasing the particle concentration of the nanoparticle in R134a, the heat transfer increases from $0.54 \%$ to $1.1 \%$ from table $\mathrm{R} 134 \mathrm{a}$ due to the thermal conductivity effect. This is due to mobility of particles near the wall, migration of them to the center of the tube.

Fig. 8 shows that the power consumption of the compressor can observe the reduction in power consumption when mixed the nanoparticle with pure refrigerant compared to pure refrigerant. A reduction of the power consumption is from $1.6 \%$ to $3.3 \%$.

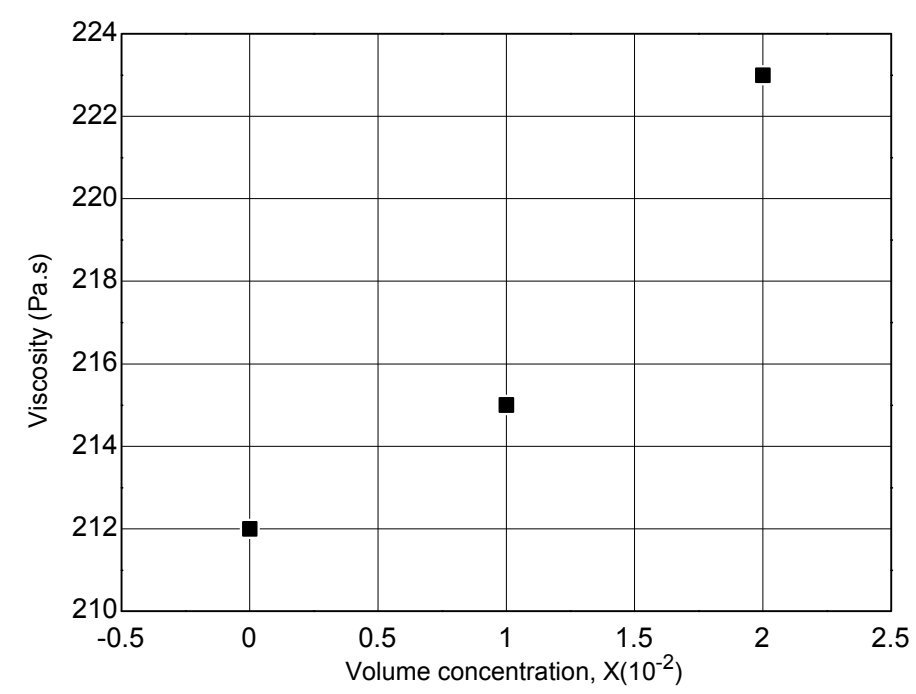

Fig. 3 Viscosity as a function of volume concentration $\mathrm{Al}_{2} \mathrm{O}_{3}$. 


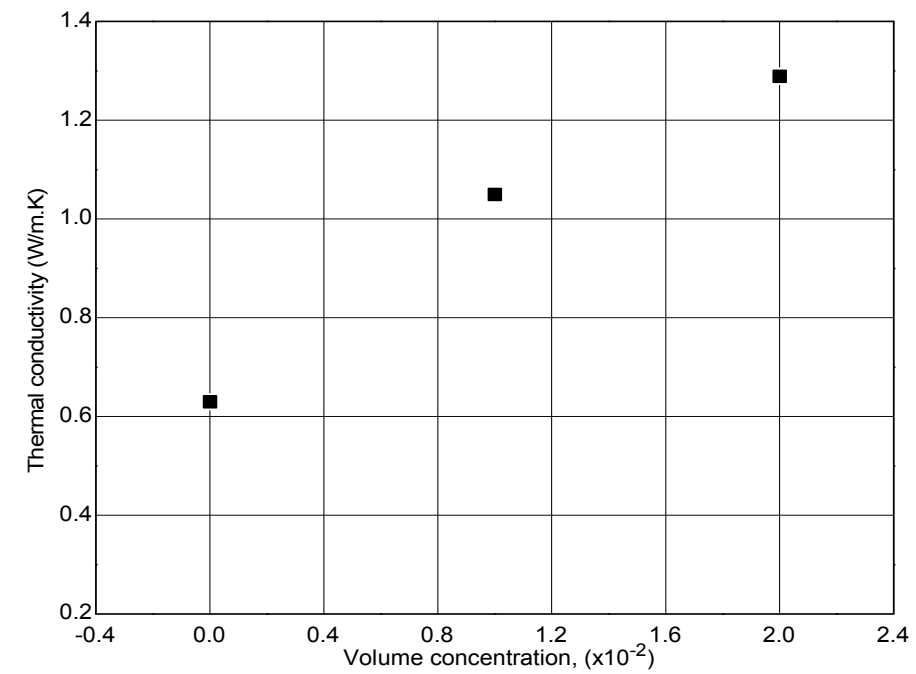

Fig. 4 Thermal conductivity as a function volume concentration.

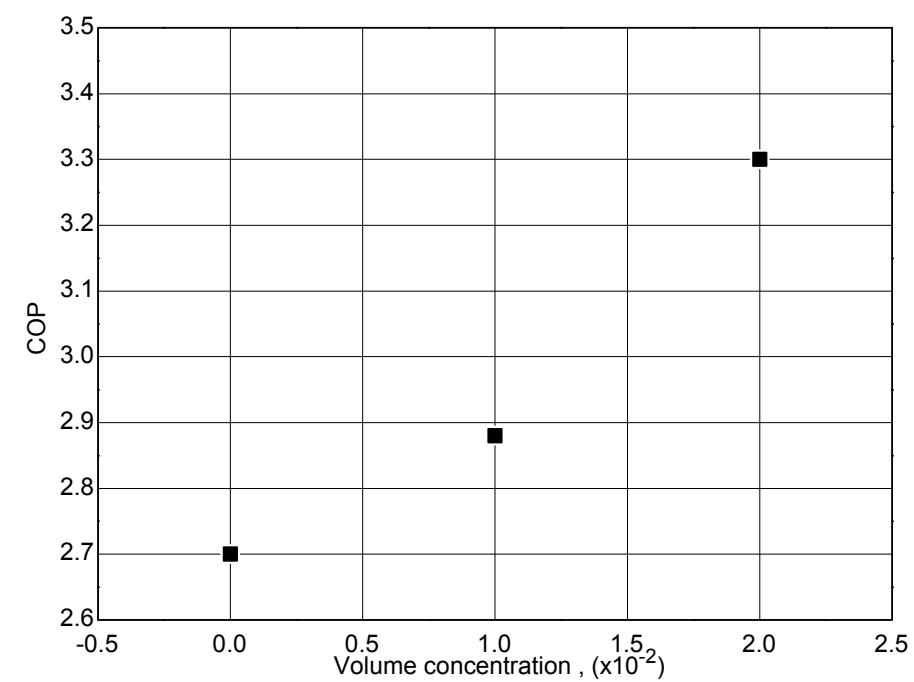

Fig. 5 Variation of COP with volume concentration.

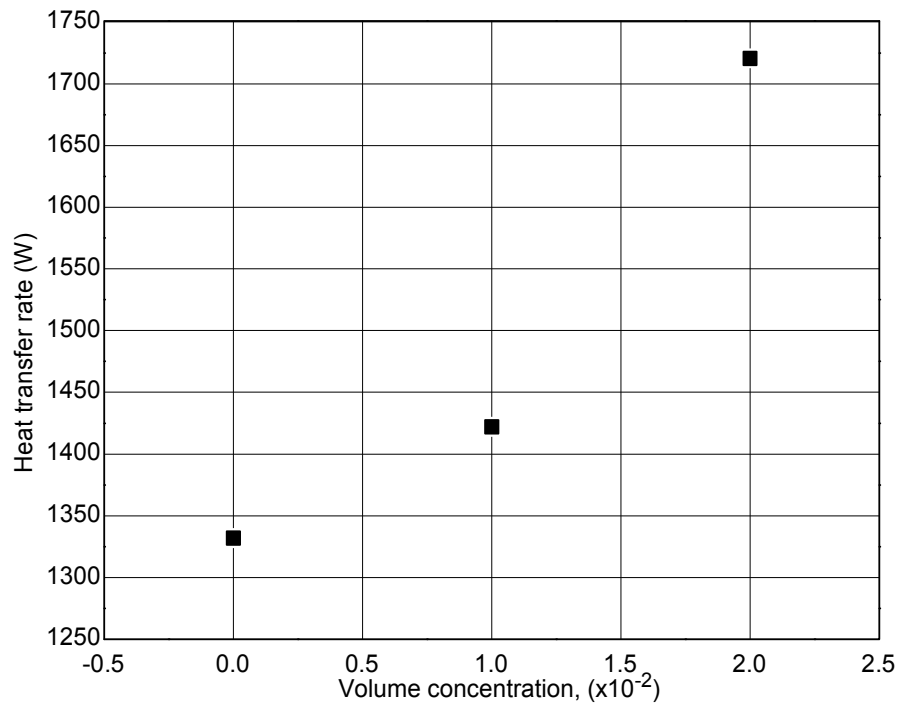

Fig. 6 Effect of volume concentration on the heat transfer rate. 


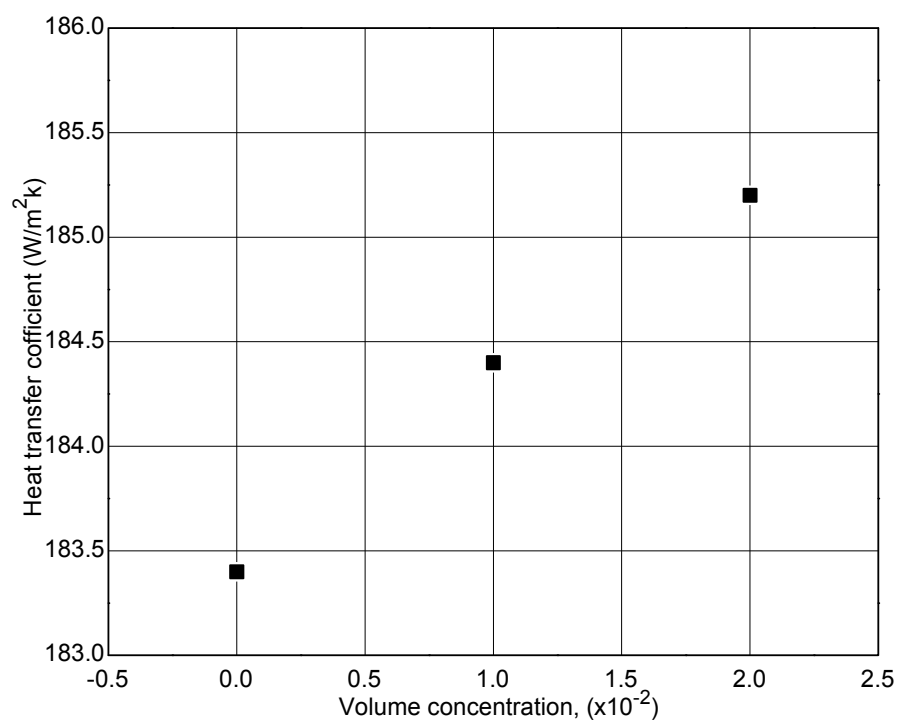

Fig. 7 Heat transfer coefficient as a function of volume concentration.

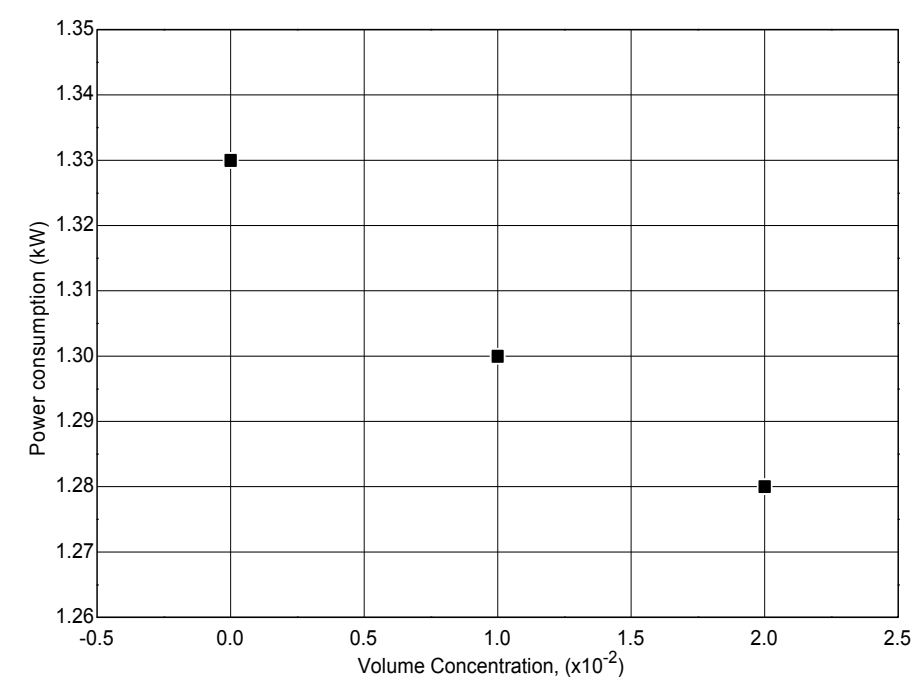

Fig. 8 Comparison of power consumption.

\section{Conclusions}

(1) The viscosity of nano-refrigerant also increases $1.4 \%$ and $5.18 \%$ with the increase of nanoparticle concentration compared with conventional refrigerant.

(2) The heat transfer coefficient increases significantly $0.54 \%$ and $1.1 \%$ respectively.

(3) The coefficient of performance for $0.01 \%$ and $0.02 \%$ of refrigerant are increased by $3.33 \%, 12 \%$ respectively.

(4) The heat transfer rate with volume fraction $0.01 \%$ and $0.02 \%$ is enhancement about $6.7 \%$ and $21.4 \%$ respectively.

(5) A reduction of the power consumption is $1.6 \%$ and $3.3 \%$ respectively.

(6) Fast cooling is from $42{ }^{\circ} \mathrm{C}$ to $16^{\circ} \mathrm{C}$.

(7) Thermal conductivity of the nano-refrigerant increases with the increased volume fraction and temperature, and decreases with increasing nanoparticle size, which is about $11.5 \%$ and $14.2 \%$ respectively.

\section{References}

[1] Senthilkumar, A., and Praveen, R. 2015. "Performance Analysis of a Domestic Refrigerator Using CUO-R600a Nano-Refrigerant as Working Fluid." Journal of Chemical and Pharmaceutical Sciences (Special Issue 9): 30-3.

[2] Bi, S. S., Guo, K., Liu, Z. G., and Wu, J. T. 2011. 
"Performance of a Domestic Refrigerator Using $\mathrm{TiO}_{2}$-R600a Nano-Refrigerant as Working Fluid." Energy Conversion and Management 52 (1): 733-7.

[3] Kuljeet, S., and Kundan, L. 2014. "An Investigation into the Performance of a Nanorefrigerant $\left(\mathrm{R} 134 \mathrm{a}+\mathrm{Al}_{2} \mathrm{O}_{3}\right)$ Based Refrigeration System." International Journal of Research in Mechanical Engineering \& Technology 4 (2): 158-62.

[4] Mahbubul, I. M., Fadhilah, S. A., Saidur, R., Leong, K. Y., and Amalina, M. A. 2013. "Thermophysical Properties and Heat Transfer Performance of $\mathrm{Al}_{2} \mathrm{O}_{3} / \mathrm{R}-134 \mathrm{a}$ Nanorefrigerants." International Journal of Heat and Mass Transfer 57 (1): 100-8.

[5] Fadhilah, S. A., Marhamah, R. S., and Izzat, A. H. M. 2014. "Copper Oxide Nanoparticles for Advanced Refrigerant Thermophysical Properties, Mathematical Modeling." Journal of Nanoparticles 2014 (April): 1-5.

[6] Tarun, S., and Kundan, L. R. 2015. "An Experimental Investigation of Nanorefrigerant Based Refrigeration System." International Journal of Electronics, Electrical and Computational System 4: 317-9.

[7] Bi, S., Guo, K., Liu, Z., and Wu, J. 2011. "Performance of a Domestic Refrigerator Using $\mathrm{TiO}_{2}-\mathrm{R} 600 \mathrm{a}$ Nano-Refrigerant as Working Fluid." Energy Conversion and Management 52 (1): 733-7.

[8] Eiyad, A.-N. 2008. "Applications of Nanofluids for Heat Transfer Enhancement of Separated Flows Encountered in a Backward Facing Step." International Journal of Heat and Fluid Flow 29 (1): 242-9.

[9] Mahbubul, I. M., Saidur1, R., and Amalina, M. A. 2012. "Investigation of Viscosity of R123-TIO2 Nanorefrigerant." International Journal of Mechanical and Materials Engineering 7 (2): 146-51.

[10] Brinkman, H. 1952. "The Viscosity of Concentrated Suspensions and Solutions." The Journal of Chemical Physics 20 (4): 571.

[11] Vasu, V., Krishna, K. R., and Kumar, A. C. S. 2008. "Empirical Correlations to Predict Thermophysical and Heat Transfer Characteristics of Nanofluids." Journal of Thermal Science 12 (2): 27-37.

[12] Reza, A., Heydar, M., Malihe, Z., Mehdi, D., and Sahar, G. K. M. 2014. "Heat Transfer of Nanofluid in a Double Pipe Heat Exchanger." International Scholarly Research Notices 2014 (November): 1-7.

[13] Jaafar, J. A. 2015. "Performance Improvement of an Air-Conditioning System during Refrigerant Condensation." M.Sc. thesis, College of Engineering Al-Mustansiriyah University. 